\title{
Phyllosphere Colonization by a Soil Streptomyces sp. Promotes Plant Defense Responses Against Fungal Infection
}

\author{
Sophie Vergnes, ${ }^{1}$ Damien Gayrard, ${ }^{1,2}$ Marine Veyssière, ${ }^{1}$ Justine Toulotte, ${ }^{1}$ Yves Martinez, ${ }^{3}$ \\ Valérie Dumont, ${ }^{4}$ Olivier Bouchez, ${ }^{5}$ Thomas Rey, ${ }^{1,2,+}$ and Bernard Dumas ${ }^{1, \dagger}$ \\ ${ }^{1}$ Laboratoire de Recherche en Sciences Végétales, Université de Toulouse, CNRS, UPS, France \\ ${ }^{2}$ De Sangosse, Bonnel, 47480 Pont-Du-Casse, France \\ ${ }^{3}$ CNRS, Plateforme Imagerie-Microscopie, Fédération de Recherche FR3450, Castanet-Tolosan, France \\ ${ }^{4}$ CRITT-Bio-industries, INSA, 135 avenue de Rangueil, 31077 Toulouse Cedex 4, France \\ ${ }^{5}$ INRA, US 1426, GeT-PlaGe, Genotoul, Castanet-Tolosan, France
}

Accepted 19 September 2019.

Streptomycetes are soil-dwelling, filamentous actinobacteria and represent a prominent bacterial clade inside the plant root microbiota. The ability of streptomycetes to produce a broad spectrum of antifungal metabolites suggests that these bacteria could be used to manage plant diseases. Here, we describe the identification of a soil Streptomyces strain named AgN23 which strongly activates a large array of defense responses when applied on Arabidopsis thaliana leaves. AgN23 increased the biosynthesis of salicylic acid, leading to the development of salicylic acid induction deficient 2 (SID2)-dependent necrotic lesions. Size exclusion fractionation of plant elicitors secreted by $\mathrm{AgN23}$ showed that these signals are tethered into high molecular weight complexes. AgN23 mycelium was able to colonize the leaf surface, leading to plant resistance against Alternaria brassicicola infection in wild-type Arabidopsis

S. Vergnes and D. Gayrard contributed equally to this article.

${ }^{\dagger}$ Corresponding authors: B. Dumas; dumas@lrsv.ups-tlse.fr; and T. Rey; reyt@desangosse.com

Funding: This work was funded by the Fond Unique Interministériels (NEOPROTEC project), the Fonds Européen de Développement Économique et Régional (FEDER), and the Agence Nationale de la Recherche (LabCom BioPlantProtec ANR-14-LAB7-0001 and STREPTOCONTROL ANR-17-CE20-0030). Work performed in the GeT core facility, Toulouse, France (https://get.genotoul.fr) was supported by the France Génomique National infrastructure, funded as part of the "Investissement d'Avenir" program managed by the Agence Nationale de la Recherche (contract ANR-10-INBS-09) and by the GET-PACBIO program (FEDER Programme opérationnel FEDER-FSE MIDI-PYRENEES ET GARONNE 2014-2020). D. Gayrard was funded by Agence Nationale de la Recherche Technique, with the Convention Industrielle de Formation par la Recherche and Association Nationale de la Recherche et de la Technologie (grant number 2016/1297).

*The $\boldsymbol{e}$-Xtra logo stands for "electronic extra" and indicates that seven supplementary datasets are published online.

The authors declare the following conflict of interest: B. Dumas and S. Vergnes are inventors of the patent WO2015044585A1 relating the use of AgN23 in Agriculture. T. Rey and D. Gayrard are full-time researchers in the AgChem company De Sangosse (Pont-Du-Casse, France), which registers and markets crop-protection products. M. Veyssiere, J. Toulotte, Y. Martinez, V. Dumont, and O. Bouchez declare no competing interest.

(c) 2020 The American Phytopathological Society plants. AgN23-induced resistance was found partially compromised in salicylate, jasmonate, and ethylene mutants. Our data show that Streptomyces soil bacteria can develop at the surface of plant leaves to induce defense responses and protection against foliar fungal pathogens, extending their potential use to manage plant diseases.

Keywords: Alternaria brassicicola, Arabidopsis thaliana, bacteriaplant symbiosis, biocontrol, defense signaling pathways, ethylene, jasmonate, plant defense, salicylic acid, Streptomyces

In their environment, plants have to cope with a wealth of beneficial, commensal, and pathogenic microorganisms (Berendsen et al. 2012; Vorholt 2012). Microbial consortia living around plants can alter disease progression, and manipulating the plant microbiota holds great promise to develop biocontrol solutions (Busby et al. 2017). Interactions between plants, pathogens, and the microbiota range from indirect exchange of extracellular bioactive compounds to spatial and nutrient competition around and inside plant tissues (Chaparro et al. 2013, 2014; Stringlis et al. 2018b). Unlike pathogens, beneficial microbes can live inside plant tissues (endophytes) or at the surface (rhizoplane) or around (rhizosphere) plants roots and leaves without causing symptoms (Bergelson et al. 2019). The activation of plant defense by such microbes often enhances disease resistance to subsequent pathogen invasion (Bhattacharyya and Jha 2012). Efficient plant defense mechanisms include preexisting physical and chemical barriers as well as immune responses triggered by the perception of molecular patterns exposed by pathogens upon plant colonization (van Loon et al. 1998). Pathogen-associated molecular patterns (PAMPs) or microbial-associated molecular patterns such as flagellin, elongation factor, or peptidoglycans interact with dedicated plant cell receptors, the pattern recognition receptors, which activate PAMP-triggered immunity (PTI) responses (Boller and Felix 2009; Stringlis et al. 2018a; Zipfel 2008). The activation of hallmark PTI marker genes is largely dependent on salicylic acid (SA) signaling; nonetheless, defense responses also involve interplays with jasmonic acid (JA) and ethylene (ET) signaling and biosynthesis (Pieterse et al. 2012). In Arabidopsis, SA biosynthesis by the isochorismate synthase gene salicylic acid induction deficient 2 (SID2) mediates most of the SA biosynthesis in the plant in stress responses (Ferrari et al. 2003; 
Wildermuth et al. 2001). SA-dependent responses are prominently active against biotrophic pathogens and are associated with the local and systemic induction of pathogenesis-related (PR) proteins such as PR1 (Bürger and Chory 2019). By contrast, the defense pathways regulated by JA or ET are particularly important for the resistance against necrotrophic pathogens and interact antagonistically with the SA pathway (Bürger and Chory 2019). Collectively, the balance between these pathways enables plant resistance to most foliar pathogens. It is noteworthy that these disease resistance mechanisms can be activated locally as well as systemically by JA for induced systemic resistance and SA for systemic acquired resistance (Carvalhais et al. 2015; Pieterse et al. 2014; van Loon et al. 1998; Wang et al. 2018).

Modern agriculture faces the challenge to reduce pesticide use while pests develop resistance mechanisms to chemical active ingredients. New discoveries of fungicidal substances with acceptable ecotoxicological and toxicological features are becoming rare. Therefore, the use of microbial strains or the design of synthetic bacterial communities as biocontrol agents could represent an attractive alternative to ensure high yield (Syed Ab Rahman et al. 2018). Although a number of bacterial and fungal strains are currently included in commercial preparations aiming to protect plants against diseases (Bhattacharyya and Jha 2012; Syed Ab Rahman et al. 2018), identification of new beneficial microbial species is required to optimize this approach.

Among the most promising candidates are Gram-positive bacteria belonging to the genus Streptomyces, which constitutes a prominent component in the plant rhizosphere (Lundberg et al. 2012; Rey and Dumas 2017; Viaene et al. 2016; Vurukonda et al. 2018). These filamentous bacteria inhabit both soils and aquatic environments and can disseminate in the air (Palaniyandi et al. 2013; Rey and Dumas 2017; SarmientoVizcaíno et al. 2016; Schrey and Tarkka 2008). Streptomycetes are extremely rarely pathogens (Armijos-Jaramillo et al. 2017; Joshi et al. 2007); by contrast, they are beneficial or commensal symbionts in a wide range of plants and invertebrates (Seipke et al. 2012). Numerous examples of plant-colonizing Streptomyces spp. have been reported (Cao et al. 2016; Hassan et al. 2017; Li et al. 2018; Mingma et al. 2015; Ondrejíčková et al. 2016; van der Meij et al. 2018). Rhizospheric and endophytic Streptomyces spp. are often able to modulate plant growth (Niu et al. 2016; Olanrewaju and Babalola 2019; Vurukonda et al. 2018), potentially by producing diverse phytohormones (Rashad et al. 2015). Complementarily, streptomycetes isolated in natura from Arabidopsis respond to plant hormones by producing specialized secondary metabolites (van der Meij et al. 2018). Streptomyces spp. also interact in the rhizosphere with other microbes, thereby suppressing plant diseases caused by telluric pathogenic fungi (Bakker et al. 2014; Cordovez et al. 2015; Kinkel et al. 2012; Schrey and Tarkka 2008). As an example, the hallmark antibiotic streptomycin is strongly produced by a rhizospheric Streptomyces strain during Arabidopsis bolting and flowering, presumably protecting plants from pathogens (Chaparro et al. 2014). By contrast, other Streptomyces strains support growth of ectomycorrhizal fungi (Riedlinger et al. 2006; Schrey et al. 2005, 2007; Tarkka et al. 2015). Although Streptomyces spp. are prominently found in roots, a few examples of leaf colonizers have been reported; however, this type of interaction has been widely overlooked (Mingma et al. 2015; Shimizu et al. 2000).

Hitherto, most Streptomyces spp. evaluated as biocontrol agents were solely screened based on their antifungal properties, neglecting the potential of plant defense stimulation raised by root colonization (Conn et al. 2008; Hamedi and Mohammadipanah 2015; Shao et al. 2018). In agriculture, attempts to use streptomycetes for biocontrol of fungal diseases led to the development of soil amendment products such as Actinovate (Streptomyces lydicus WYEC 108) and Mycostop (S. griseoviridis K61). However, Streptomyces spp. application into soils remains a technical bottleneck and applying Streptomyces spp. as foliar treatment is a desirable approach. In this work, we report on the biological activities of a new Streptomyces strain on Arabidopsis. We show that this strain is able to transiently develop at the surface of plant aerial tissues and produce extracellular elicitors of plant defense reactions, leading to protection against fungal pathogens.

\section{RESULTS}

\section{Streptomyces AgN23 produces elicitors leading to induction of PR1 gene expression in Arabidopsis seedlings among a range of Streptomyces spp.}

In a search of new soil bacteria stimulating plant defense responses, soil samples were collected from the rhizosphere of field-located grape roots and 32 actinomycete strains were isolated. The screening of these strains was based on the induction of PRI gene expression, using a reporter line expressing the $\beta$-glucuronidase gene uidA (hereafter referred to as $G U S$ ) under the control of the PR1 promoter (Shapiro and Zhang 2001). The 32 actinomycetes were grown in liquid flasks for 1 week before the culture media was collected and applied to hydroponically grown Arabidopsis Col-0 PR1::GUS at a final concentration of $1 \%$ (Fig. 1A). Based on these results, the strain AgN23 was selected, considering its specific ability to strongly activate the GUS gene. Analysis of the AgN23 16S ribosomal RNA (rRNA) sequence (GenBank JN104730.1) revealed a strong homology with $S$. castelarensis, belonging to the $S$. violaceusniger 16 rRNA clade (Supplementary Dataset S1) (Goodfellow et al. 2007; Kumar and Goodfellow 2008; Kumar et al. 2007). Then, induction of the GUS gene was validated on plants grown in pots and treated with AgN23 extracellular culture medium harvested after 1 to 6 days of culture. To address the duration of defense induction following initial treatment of plants grown in pots, we sprayed leaves with mock media (0 day) and AgN23 culture media harvested after $1,2,4$, and 6 days of culture, then tracked the GUS activity in Arabidopsis 5, 7, or 14 days posttreatment (hpt) (Fig. 1B). The elicitor activity released by the bacteria reached its maximum after 6 days of culture, resulting in transient induction of plant defense, which gradually decreased after 5 days (Fig. 1B).

\section{Streptomyces AgN23 produces extracellular compounds inducing a broad spectrum of immune responses in Arabidopsis seedlings.}

An RNA sequencing (RNAseq) approach was devised to decipher earlier events in plant response to AgN23 extracellular culture media and get a comprehensive view of plant immunity activation. Arabidopsis seedlings were immerged in Murashige and Skoog (MS) medium containing the AgN23 culture media and harvested 1 or 6 hpt. Pairwise comparisons between biological triplicates of treated and untreated plants were calculated at each time point of the kinetic to identify differentially expressed genes (Supplementary Dataset S2). Genes showing a fold change (FC) greater than 1 or less than -1 in a $\log _{2}$ base and a false discovery rate $(\mathrm{FDR})<0.001$ were considered for subsequent analyses (Fig. 2A; Supplementary Datasets S2 and 3 ). This dataset was validated by selecting a set of 28 genes transcriptionally regulated in the RNAseq data and confirming their induction by reverse-transcription quantitative PCR (RTqPCR) $\left(R^{2}=0.77\right)$ (Fig. 2B). At $1 \mathrm{hpt}$, we found 249 regulated genes, among which $74 \%$ were induced (Supplementary Dataset S3). Similarly, of 1,304 regulated genes at $6 \mathrm{hpt}, 987$ 
genes showed induction (Supplementary Dataset S4). The examination of commonly induced genes at 1 or $6 \mathrm{hpt}$ showed that their induction was stronger at $6 \mathrm{hpt}$ (130 of 139) (Fig. 2C; Supplementary Dataset S5). These data suggest that the Streptomyces AgN23 supernatant triggered a quick induction of plant responses, gradually increasing over time.

To get a first hint into the processes affected by bacterial supernatant treatment, we characterized the 485 genes showing $\log _{2} \mathrm{FC}>2$ at $6 \mathrm{hpt}$ using the gene ontology(GO) classification based on the Arabidopsis TAIR10 genome. These genes were classified in 117 different GO terms belonging to "Biological Processes". GO term enrichment analysis was then summarized and visualized using REVIGO (Fig. 2D; Supplementary Dataset S6) (Supek et al. 2011). The analysis emphasized a cluster around the "defense response" GO term. Other close and highly significantly represented GO terms are "immune response", "response to stress", "response to external stimulus", "response to organonitrogen compound" that is the parent GO term of "chitin response", and "hormone response". Similarly, we detected strong enrichment in "response to external biotic stimulus" that is the parent GO terms of "response to bacterium", "response to fungus", and "systemic acquired resistance". Other enriched GO terms were linked to disease resistance; notably, GO terms corresponding to lignin and phenylpropanoid pathways and secondary metabolism components such as "phytoalexin biosynthetic" that are collectively child terms of the parent GO "toxin metabolic process" (Fig. 2D).

Among the 241 genes showing the strongest $\log _{2} \mathrm{FC}>3$ at 6 hpt, 83 genes had a predicted function, most of them being related to defense responses (Supplementary Dataset S7). This analysis revealed the induction of a large number of putative receptor genes, transcription factors, and genes involved in signaling pathways, oxidative stress, secondary metabolism and cell walls, and PR proteins. Interestingly, treatments with AgN23 extracellular medium strongly induced several genes encoding P450 enzymes involved in glucosinolate metabolism, notably leading to the synthesis of camalexin, a major antimicrobial compound (Rajniak et al. 2015). Biosynthetic genes were found to be coordinately expressed with the gene coding a MYB transcription factor (MYB122) involved in the regulation of camalexin biosynthetic genes (Frerigmann et al. 2015). Overall, transcriptomic data strongly support the intense activation of plant defense responses mounted by AgN23-derived compounds released in the culture supernatant.

\section{Arabidopsis foliar responses to perception of AgN23- derived compounds and bacterial cell inoculation.}

To address whether adult Col- 0 rosettes grown in pots also respond to $\mathrm{AgN} 23$, we analyzed the immune responses induced by extracellular compounds or viable bacterial cells following foliar treatments. Expression of immune responses was monitored with 58 markers corresponding to housekeeping genes and various classes of immune and hormonal responses previously validated to investigate Arabidopsis defense responses (Vergnes et al. 2014). Treatments with 10-fold dilution of culture media were able to activate diverse defense processes, with the exception of JA-responsive genes (Fig. 3). By contrast, JA genes (ATHCHIB, AT3G12500; and the defensin PDF1.2, AT5G44420) were strongly induced by bacterial cell treatment (Fig. 3). Also, we observed that JA-related responses triggered by bacterial cells did not compromise the activation of SAresponsive genes (wall-associated kinase 1, AT1G21250; PR1, AT2G14610; PR5, AT1G75040; WRKY70, AT3G56400; and ANKYRIN, AT5G54610) (Fig. 3). Taken together, these data confirmed that $\mathrm{AgN} 23$ can modulate immune responses in adult plants and suggests that bacterial cell treatment leads to coincident SA- and JA-related plant responses.

\section{Streptomyces sp. AgN23 produces extracellular necrotic elicitors present in high molecular weight fractions.}

To characterize the compounds released by $\mathrm{AgN} 23$ in its extracellular culture medium, we performed a sequential molecular weight size fractionation of a 5-day-old culture by membrane filtration. Six fractions of increasing molecular weight $(<5 \mathrm{kDa}$ to $>100 \mathrm{kDa})$ were sprayed on $P R 1:: G U S$ plants grown in pots. We observed that only a high molecular weight fraction ( $>100 \mathrm{kDa}$ ) induced GUS expression (Fig. 4A).
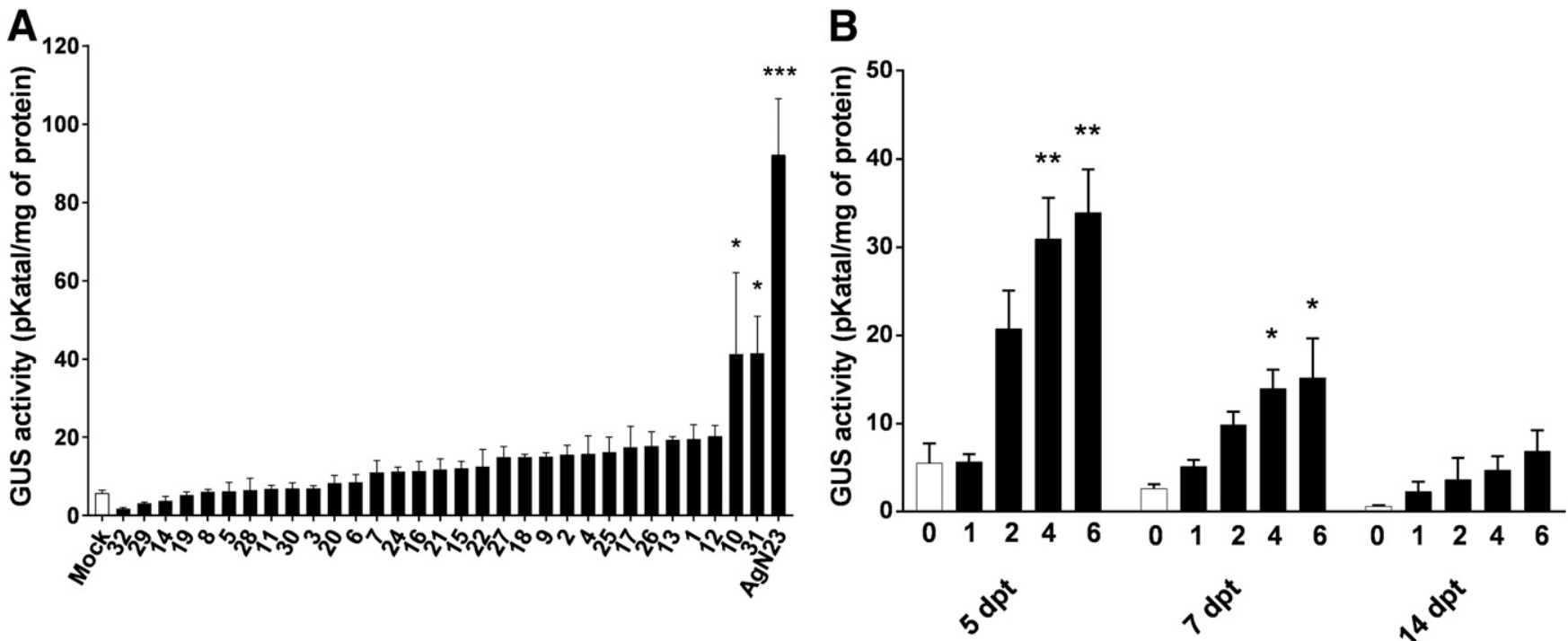

Fig. 1. Production of plant defense elicitor by Streptomyces AgN23 strain. A, Screening of bacterial culture media of 32 Streptomyces sp. strains cultivated for 6 days by treatment in hydroponic condition of the Arabidopsis thaliana Col-0 PR1::GUS line and measurement of $\beta$-glucuronidase (GUS) activity 2 days posttreatment (dpt). B, Samples of the culture media were harvested at 1, 2, 4, and 6 days of cultivation and used for foliar treatment of Col-0 PR1::GUS Arabidopsis seedlings grown for 3 weeks prior to treatment. GUS enzymatic activity was recorded at 5, 7, and 14 dpt. One-way and two-way analysis of variance followed by Dunnett's multiple comparison test were performed for A and B, respectively, to identify results statistically divergent from the control conditions $(*, * *$, and $* * *$ indicate $P<0.05,0.01$, and 0.001 , respectively). Error bars represent the standard error to the mean and $n=3$ for each condition. 
During these experiments, leaves treated with AgN23 culture medium frequently developed necrotic spots $48 \mathrm{hpt}$ (Fig. 4B) which could be stained with Trypan Blue (Fig. 4C), suggesting that necrotic elicitors are produced by $\mathrm{AgN} 23$. To determine whether the development of necrotic lesions was due to the production of phytotoxic compounds or the consequence of a strong induction of defense responses, sid2-2 plants, which are unable to form an SA-dependent cell death response, were treated with AgN23 culture filtrate or cells. No lesion was observed on sid2-2 leaves (Fig. 5A), suggesting that accumulation of SA is required for their formation. Determination of total SA concentration in treated leaves confirmed that treatment with AgN23 culture medium or AgN23 cells strongly induced the synthesis of SA, which can act as a signal for the development of a programmed cell death leading to the formation of hypersensitive-like lesions (Fig. 5B).

\section{Leaves surface colonization by AgN23 induces resistance to fungal pathogens.}

The behavior of AgN23 on leaf surfaces was followed by scanning electron microscopy at various times upon spraying of AgN23 bacterial suspension. Bacterial hyphae rapidly colonized the surface, including trichomes (Fig. 6A). In some cases, filaments terminated with vesicle-like structures referred to as sporangium in some actinobacteria (Fig. 6B) (Barka et al. 2015). Similarly to previous phyllosphere colonization reports of Streptomyces spp., AgN23 colonized stomata and penetration attempts induced local necrotic responses (Fig. 6C) (Minamiyama et al. 2003). To evaluate the protective effect of AgN23 on plant disease, Arabidopsis mutant lines defective in immunity hormone signaling were compared. In addition to sid2-2, mutant lines tested included jasmonate resistant 1 (jarl1), which is deficient for the jasmonate-amido synthetase

\section{A

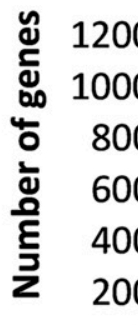

C

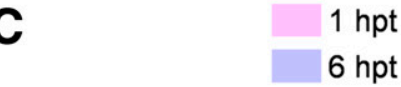

$\log 2 \mathrm{FC}>1$

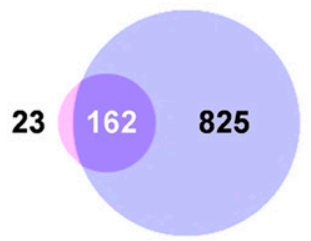

$\log 2 \mathrm{FC}>2$

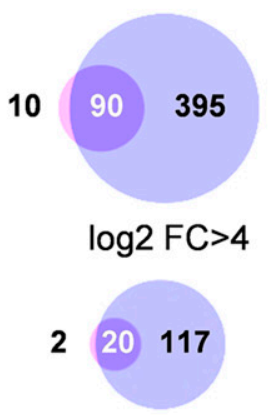

987

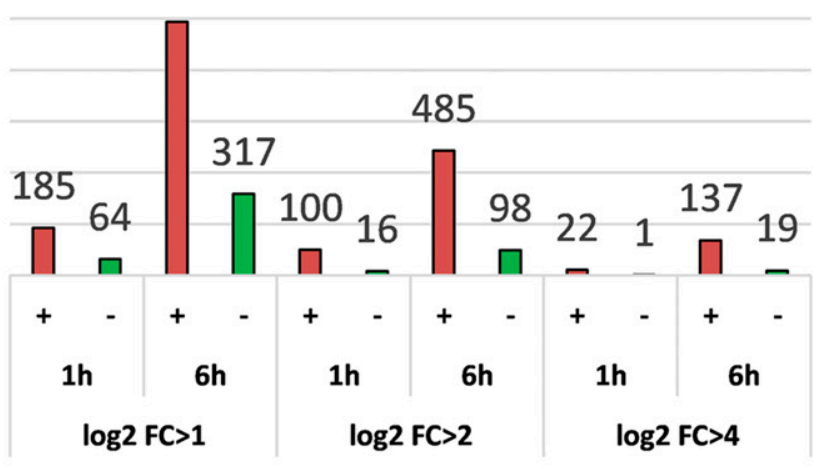

B

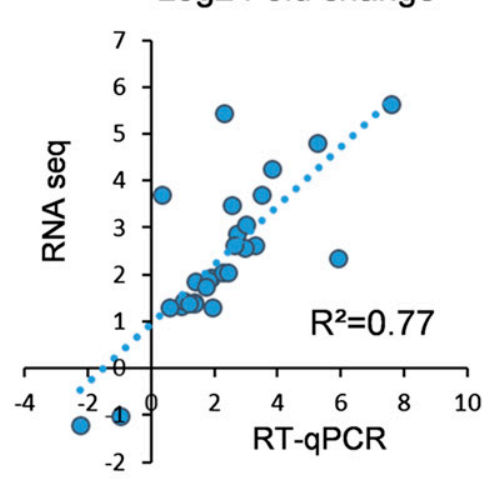

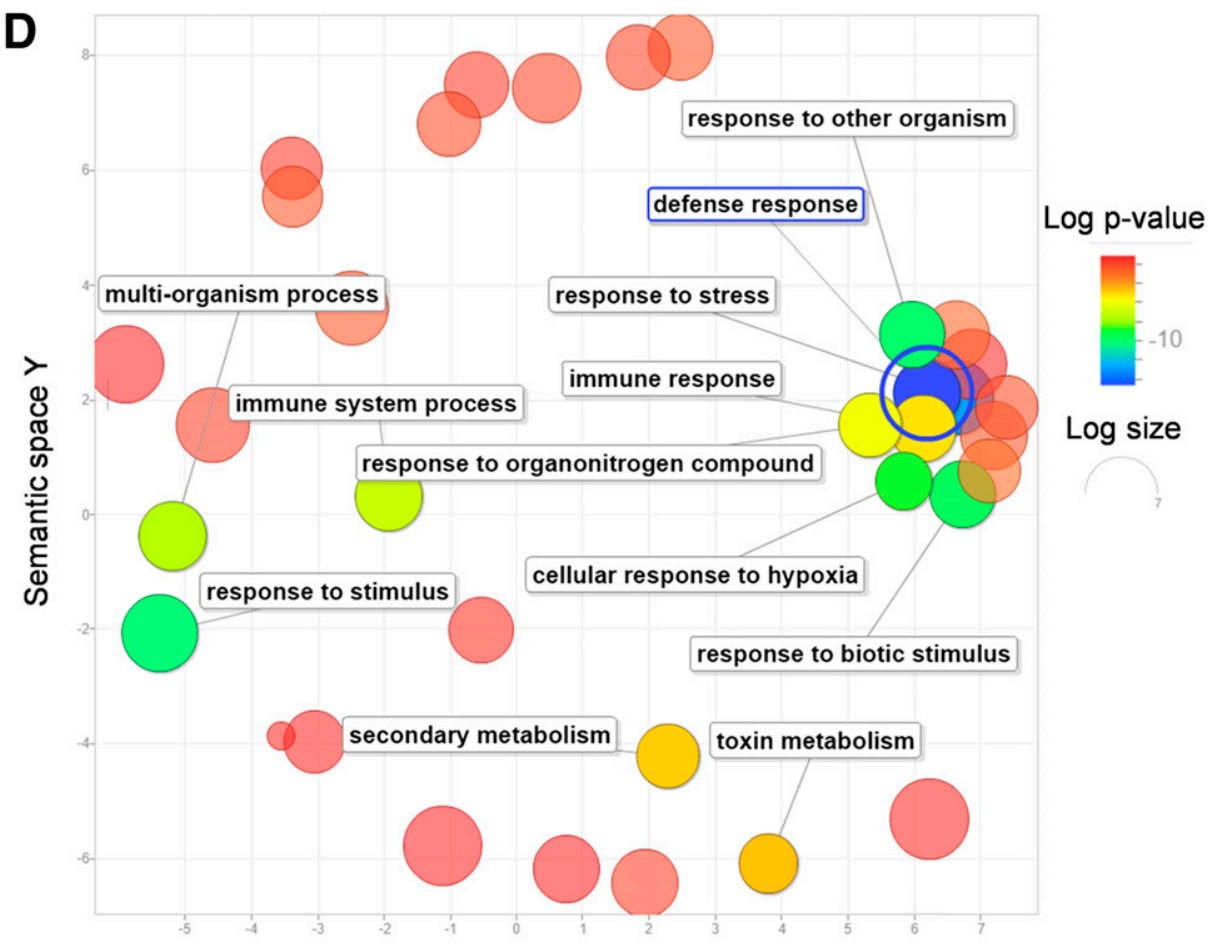

Semantic space $\mathbf{X}$

Fig. 2. Transcriptional responses to treatment with $\mathrm{AgN} 23$ culture media. A, Number of genes showing transcriptional induction $(+)$ or repression $(-)$ based on $\log _{2}$ fold change $(\mathrm{FC})>|1|$ and a false discovery rate-corrected $P$ value $<0.001$. Red bars $=$ upregulated genes and green bars $=$ downregulated genes. B, Validation of RNA sequencing (RNAseq) results by reverse-transcription quantitative PCR (RT-qPCR). C, Comparison of pool of genes regulated by AgN23 culture media treatment at 1 and $6 \mathrm{~h}$ posttreatment (hpt). D, REVIGO semantic plot of gene ontologies corresponding to the gene set showing $\log _{2} \mathrm{FC}>|1|$ at 6 hpt. Each condition corresponds to $n=3$ biological replicates. 
converting JA to isoleucine-jasmonate, and ethylene insensitive 2 (ein2), which is deficient for ET perception (Alonso et al. 1999; Ferrari et al. 2003; Kawamura et al. 2009; Li et al. 2015; Varma Penmetsa et al. 2008; Wang et al. 2007). Aerial tissues of the wild-type and mutant lines were sprayed with bacterial biomass and inoculated $48 \mathrm{~h}$ later in a detached-leaf assay with the necrotrophic pathogen Alternaria brassicicola. AgN23 treatment resulted in a strong decrease of visual necrotic lesions at 6 days postinoculation (dpi) in both the wild type and all mutants (Fig. 7). In support of this observation, we carried out Trypan Blue staining at the end of the assay and observed a strong blue coloration caused by A. brassicicola necrotrophic colonization in the leaf center of control plants. By contrast, Col-0 and mutant plants treated with AgN23 showed discrete necrotic regions similar to those observed in Figure 4C, and this pattern was conserved upon subsequent inoculation with the fungus, suggesting that AgN23 prevented the establishment of necrotrophic colonization. Complementarily, the fungal development was quantified by counting conidia produced on the leaves at $6 \mathrm{dpi}$. In the Col-0 line, reduced amounts of conidia were observed upon treatment with $\mathrm{AgN} 23$. However, this sporulation was not significantly affected in sid2-2, jarl-1, and ein2 mutants (Fig. 8), suggesting that induction of defense responses involving SA and JA or ET pathways could participate in the restriction of fungal development. Taken together, these results suggest that, although protection in AgN23-treated leaves mostly relies on plant defense responses, we cannot rule out direct effects of the Streptomyces strains on A. brassicicola development on the phylloplane.

\section{DISCUSSION}

By screening a selection of 32 Streptomyces strains isolated from soil, we identified one strain, termed $\operatorname{AgN} 23$, which we found to be a strong and selective inducer of the $P R 1$ gene in Arabidopsis thaliana among all the strains tested. To decipher plant responses to $\mathrm{AgN} 23$, we used transcriptomic study of A. thaliana responses to AgN23 culture media. We showed that AgN23 culture media can trigger a broad range of plant immune responses, including $\mathrm{JA}-$ and SA-dependent responses. Hydroponic treatment of whole seedlings with the bacterial extracellular medium led to the regulation of more than 1,000 plant genes. GO analysis showed that a large number of induced genes fall into the immunity-related functional classes and, coincidently, raised SA- and JA-related responses (Betsuyaku et al. 2018). Interestingly, AgN23 induced accumulation of SA and SA-dependent necrotic lesions on plant leaves, and microscopic examination of leaf surfaces colonized by AgN23 mycelium revealed the presence of localized stomatal cell death at the site of attempt of penetration. Taken together, our results suggest that $\mathrm{AgN} 23$ produces necrotic elicitors, leading to SA-dependent necrotic response (Lee et al. 2017).

Among the 32 actinomycetes isolates tested, the specificity of PR1 induction following treatment with AgN23 culture media suggests that the strain produces specific compounds either absent or not expressed in the other strains during microbiological culture. Although the biochemical nature of elicitors produced by AgN23 remains to be identified, streptomycetes are renown to secrete extracellular enzymes as well as a large array of antifungal and antibacterial small specialized metabolites (Chater et al. 2010). However, only a few of them have been studied for their ability to induce plant immunity. This is the case for the cellulose synthase inhibitor thaxtomin A produced by a phytopathogenic strain, S. scabies. Thaxtomin A has been shown to induce phytoalexin synthesis in Arabidopsis and tobacco and other immune responses such as cell death or calcium fluxes (Duval and Beaudoin 2009; Joglekar et al. 2018; Lerat et al. 2009). These compounds are genetically encoded into specialized metabolite biosynthetic gene clusters such as nonribosomal peptide synthase (NRPS) and polyketide synthase (PKS) (Chandra and Chater 2014;

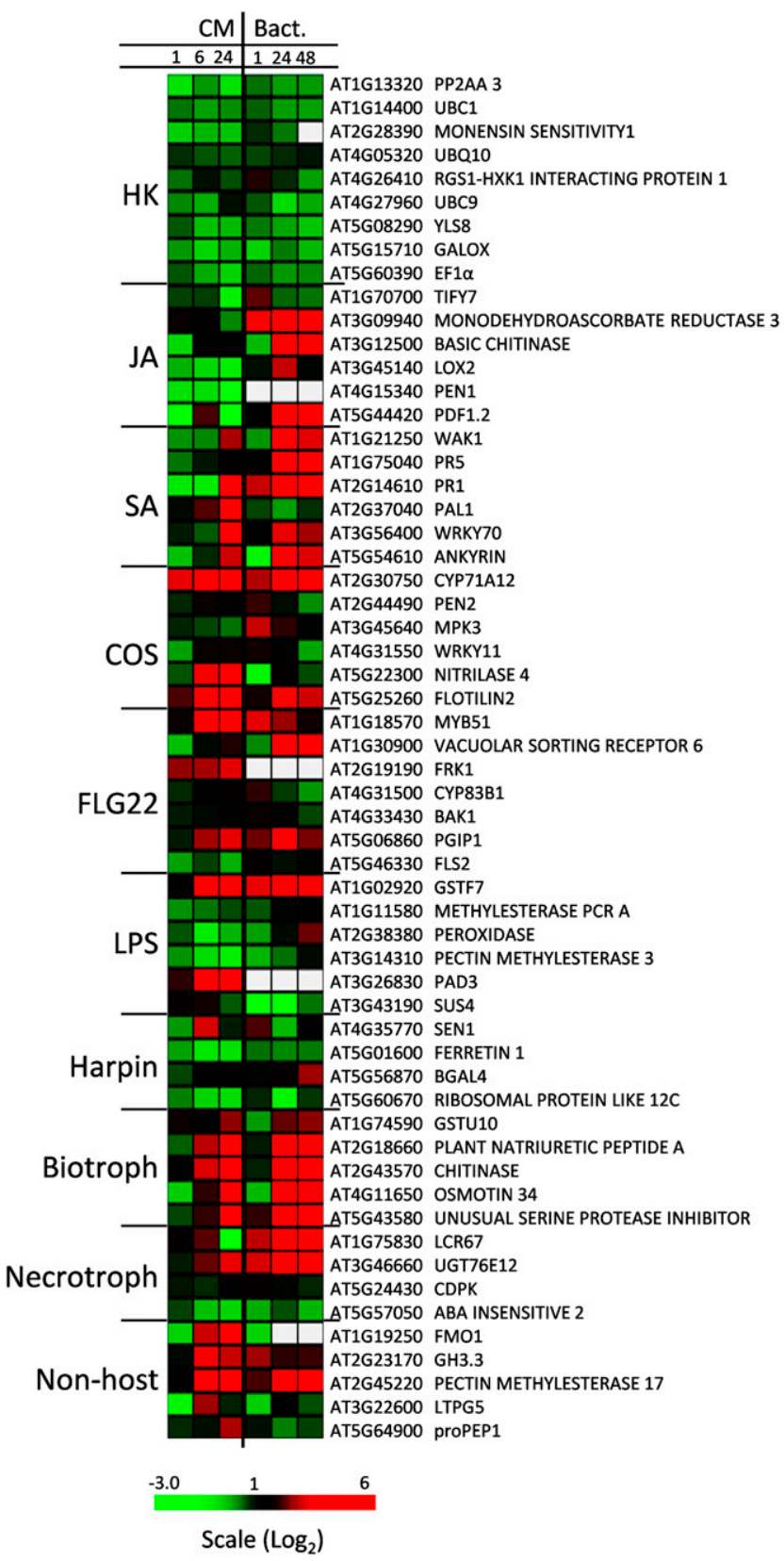

Fig. 3. Heatmap display of Arabidopsis genes regulation following treatment with AgN23 culture media (CM) or bacterial cells (Bact.). Plants grown in pots were treated by foliar spray and a set of 58 genes was studied by reverse-transcription quantitative PCR. The selection comprised housekeeping genes $(\mathrm{HK})$; genes induced by phytohormones (salicylic acid [SA] and jasmonic acid [JA]), microbial pathogen-associated molecular patterns (flagellin [flg22], chitosaccharides [COS], harpin, and lipopolysaccharides [LPS]); genes expressed upon pathogen infection (biotrophic and necrotrophic); and nonhost recognition. Genes are identified according to the TAIR10 Arabidopsis genome nomenclature. Differentially expressed genes are displayed as $\log _{2}$ fold change of treated versus untreated samples at each time point ( 1,6 , and $24 \mathrm{~h})$. Genes showing absence of regulation are in black and genes showing unreproducible expression values are displayed in white on the heatmap. Each datapoint corresponds to $n=3$ biological replicates. 
Liu et al. 2013; Niu et al. 2016). Streptomycetes can harbor contrasting lifestyles between axenic microbiological and environmental culture conditions (Jones et al. 2017). This suggests that the differences observed in defense responses following leaf treatment with culture media (inducing SA responses) and bacterial cells (inducing SA and JA responses) may be linked to differences in AgN23 elicitors released in culture media. According to our size fractionation approach, it is conceivable that elicitors are large molecular weight components of AgN23 such as peptidolglycans or other components of Gram + cell walls. However, such signals may also have been released by the other strains tested in our initial screening. Alternatively, specialized metabolites produced by NRPS or PKS are usually in the range of 0.1 to $3 \mathrm{kDa}$ but may be enclosed in large vesicular structures secreted in the media (Chater et al. 2010; Hoefler et al. 2017; Schrempf and Merling 2015; Schrempf et al. 2011).

To evaluate the effect of the induction of immune responses on the interaction with a fungal pathogen, AgN23-treated leaves were inoculated with the necrotrophic pathogen Alternaria brassicicola. Treatment resulted in decreased onset of visual symptoms in both Col-0 and immunocompromised mutants sid2, ein2, and jarl. However, the level of spores produced by the fungus 6 dpi was significantly reduced in Col0 plants but not in sid2, jarl, and ein 2 plants. This finding suggests that plant defense activation by $\mathrm{AgN} 23$ is not involved in the development of disease symptoms but may prevent the completion of fungal multiplication. This also suggests that other mechanisms such as the production of antifungal metabolites participate in the AgN23-induced protection. Because Streptomyces spp. are primarily present around plant root tissues, most studies focused on systemically induced resistance in diverse annual crops (Cao et al. 2016; Lehr et al. 2008; Zhao et al. 2012) or trees (Kurth et al. 2014). Nonetheless, a few reports showed that streptomycetes can also dwell in plant leaves (Mingma et al. 2015; Shimizu et al. 2000). Our study illustrates how a strain isolated from soil can develop on plants' aerial parts and locally activate defense responses, extending the potential use of Streptomyces spp. to protect plants against foliar diseases.

Engineering the plant microbiota is a cornerstone for the development of agronomic strategies to protect plants from diseases without chemical pesticides. Streptomycetes are major bacterial colonizers of plant roots and important microbial components of disease-suppressive soils. These bacteria are prolific producers of specialized metabolites with antibacterial and antifungal features. However, streptomycetes rarely colonize plant leaves; thus, their potential to protect crops from aerial pathogens has been neglected. We showed how a Streptomyces strain isolated from plant roots can be used to trigger
A

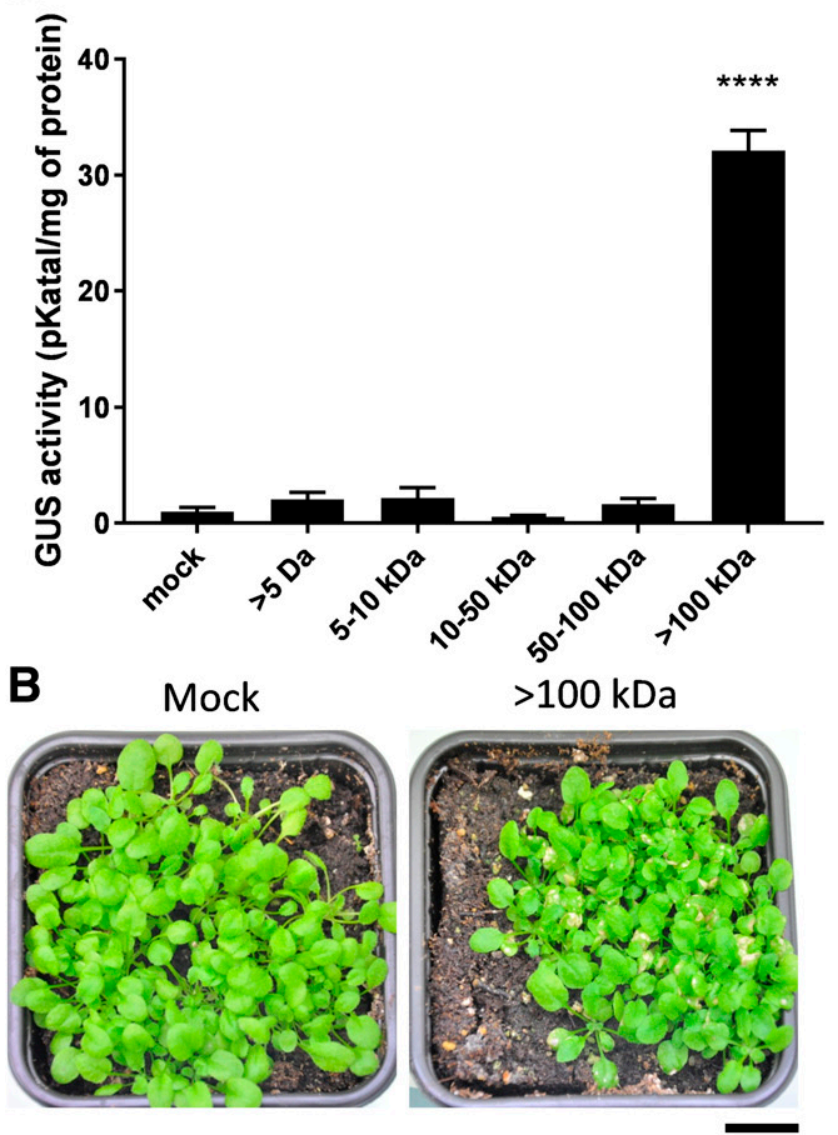

C
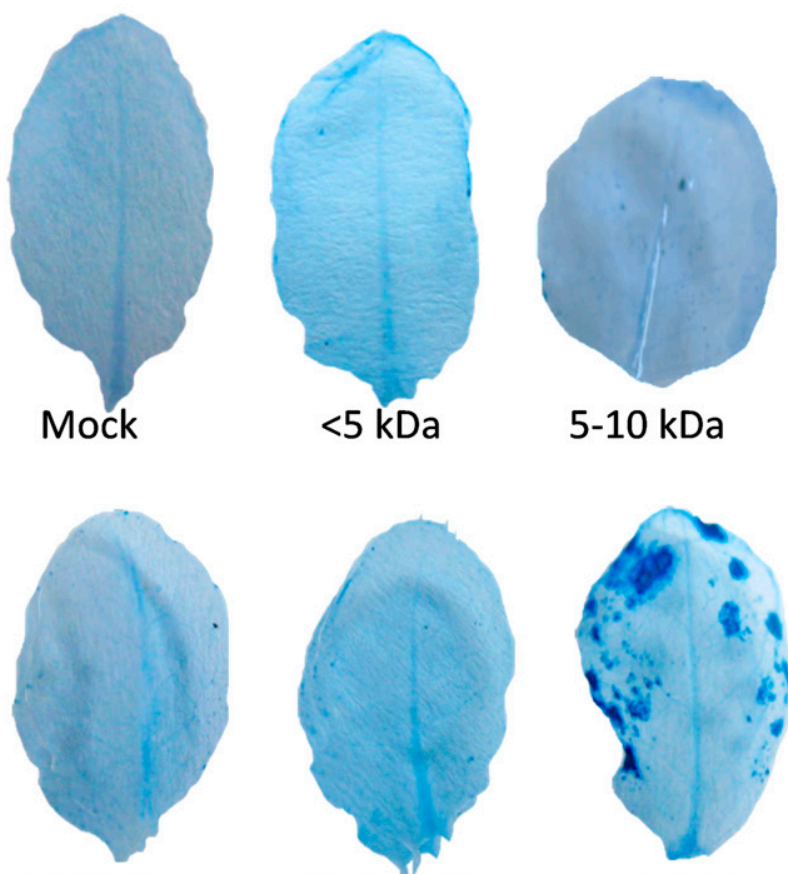

$10-50 \mathrm{kDa}$
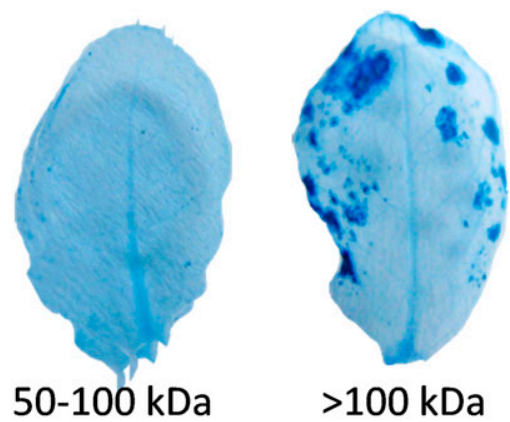

Fig. 4. AgN23 releases elicitors associated with high molecular weight fractions. Five-day-old culture media of AgN23 were subjected to sequential ultrafiltration ranging from $>100 \mathrm{kDa}$ to $>5 \mathrm{kDa}$. Fractions were sprayed on the PR1::GUS reporter line grown in pots. A, $\beta$-Glucuronidase (GUS) enzymatic activity was measured in plants $48 \mathrm{~h}$ after being sprayed with the fractions. Statistical analysis was performed using one-way analysis of variance followed by Tukey's multiple comparison test $(* * * *$ indicates $P<0.0001)$. Bars represent the standard error to the mean; each test was conducted with $n=3$ biological replicates. B, Mock and $>100 \mathrm{kDa}$ fraction-treated Col-0 PR1::GUS plants observed $48 \mathrm{~h}$ after treatment. AgN23 high molecular weight fractions induced discrete dry lesions. C, Trypan Blue staining of leaves treated with the fractions. Note the necrotic lesions following treatment with the high molecular weight fraction. Scale bars $=1 \mathrm{~cm}$. 
potent local defense responses in plant leaves and restrict colonization by fungal pathogens. This finding illustrates how soil microorganisms may be introduced into the plant phyllosphere microbiota to achieve crop protection.

\section{MATERIALS AND METHODS}

Arabidopsis thaliana lines and cultivation methods.

Arabidopsis thaliana lines used were Col-0 wild-type, transgenic line PR1::GUS (Shapiro and Zhang 2001), sid2-2 (Wildermuth et al. 2001), jarl-1 (Staswick et al. 1998), and ein2 (Alonso et al. 1999). For in vitro assays, seed were soaked in water for $40 \mathrm{~min}$, then treated for $30 \mathrm{~min}$ in $2.4 \%$ sodium hypochlorite solution, followed by four washings in sterile water. The surface-sterilized seed were transferred into wells of 24-well microtiter plates ( 2 seeds/well), containing $300 \mu \mathrm{l}$ of MS medium (Sigma-Aldrich, Saint-Quentin-Fallavier, France) supplemented with $1 \%$ sucrose. The plates were incubated under a cycle of $16 \mathrm{~h}$ of illumination and $8 \mathrm{~h}$ of night at $23^{\circ} \mathrm{C}$ on a rotary shaker at $90 \mathrm{rpm}$ for 3 days, then on a static tray for 12 days. For SA analysis and pathogenicity tests, plants were grown on soil (PROVEEN; Bas Van Buuren B.V., Holland) in a growth chamber under $12 \mathrm{~h}$ of light at $23^{\circ} \mathrm{C}$ and $12 \mathrm{~h}$ of darkness at $20^{\circ} \mathrm{C}$ for 3 weeks. Foliar treatments of 3 -week-old plants grown in pots were performed by spraying the compounds at $1 \mathrm{ml} /$ pot using a manual spray. For all the treatments, a wetting agent (Actilandes; ActionPin Cazalieu, Castets, France) was added at a final concentration of $1 \mu \mathrm{l} /$ liter.

\section{Alternaria brassicicola inoculation assay.}

Alternaria brassicicola strain Abra43 (Sellam et al. 2007) was maintained on potato dextrose agar. For pathogenicity tests, fungal spores were harvested and adjusted to $5 \times 10^{5}$ spores/ml in a Fuchs-Rosenthal counting cell (Pochon et al. 2012). Detached leaves of Arabidopsis thaliana were deposited on the agar medium and inoculation of the fungus was done by depositing a drop of $10 \mu \mathrm{l}$ on each leaf. The plates were then parafilmed to maintain high hygrometry and kept in a climate chamber for 6 days, according to the cycle $16 \mathrm{~h}$ in the light at $22^{\circ} \mathrm{C}$ and $8 \mathrm{~h}$ in the dark at $20^{\circ} \mathrm{C}$. At $6 \mathrm{dpi}$, the spores formed on symptomatic leaves were harvested by shaking three leaves in $15-\mathrm{ml}$ Falcon tubes containing $3 \mathrm{ml}$ of $0.1 \%$ Tween 20 solution. The leaves were removed from the tubes and detached spores were pelleted by centrifugation $(15 \mathrm{~min}$ at $5,000 \times g)$. The supernatant was discarded and spores resuspended in $12 \mu \mathrm{l}$ of $0.1 \%$ Tween 20 solution before counting in the FuchsRosenthal cell.

\section{AgN23 cultivation methods}

and high molecular elicitor fractionation.

The AgN23 strain was maintained and cultivated as described by Errakhi et al. (2007) and patents WO2015044584 and WO2015044585. In brief, the supernatant of AgN23 was produced from liquid shaken culture of $\mathrm{AgN} 23$ grown for 6 days in 250-ml flasks containing $50 \mathrm{ml}$ of Bennet medium. The bacterial biomass was separated from supernatant by centrifugation and the supernatant directly used for hydroponic plant treatment. For size exclusion fractionation of the elicitor activity, the supernatant was sequentially centrifuged on Vivaspin (Sartorius, Aubagne, France) ultrafiltration columns with molecular weight cut-offs of 5 to 10,10 to 50 , and 50 to $100 \mathrm{kDa}$, according to manufacturer recommendations. The eluent of $5-\mathrm{kDa}$ columns and the retentate of the $50-$ to $100-\mathrm{kDa}$ cut-off were also considered for assessment of biological activities. For inoculation of bacterial biomass on Arabidopsis plants, $1 \mathrm{ml}$ of a 7-day-old culture broth in liquid Bennet medium was directly sprayed on plants.
GUS activity assays.

The assays were conducted as described by Vergnes et al. (2014). Briefly, total proteins were extracted from $100 \mathrm{mg}$ of treated plants after grinding in liquid nitrogen, with $100 \mu \mathrm{l}$ of
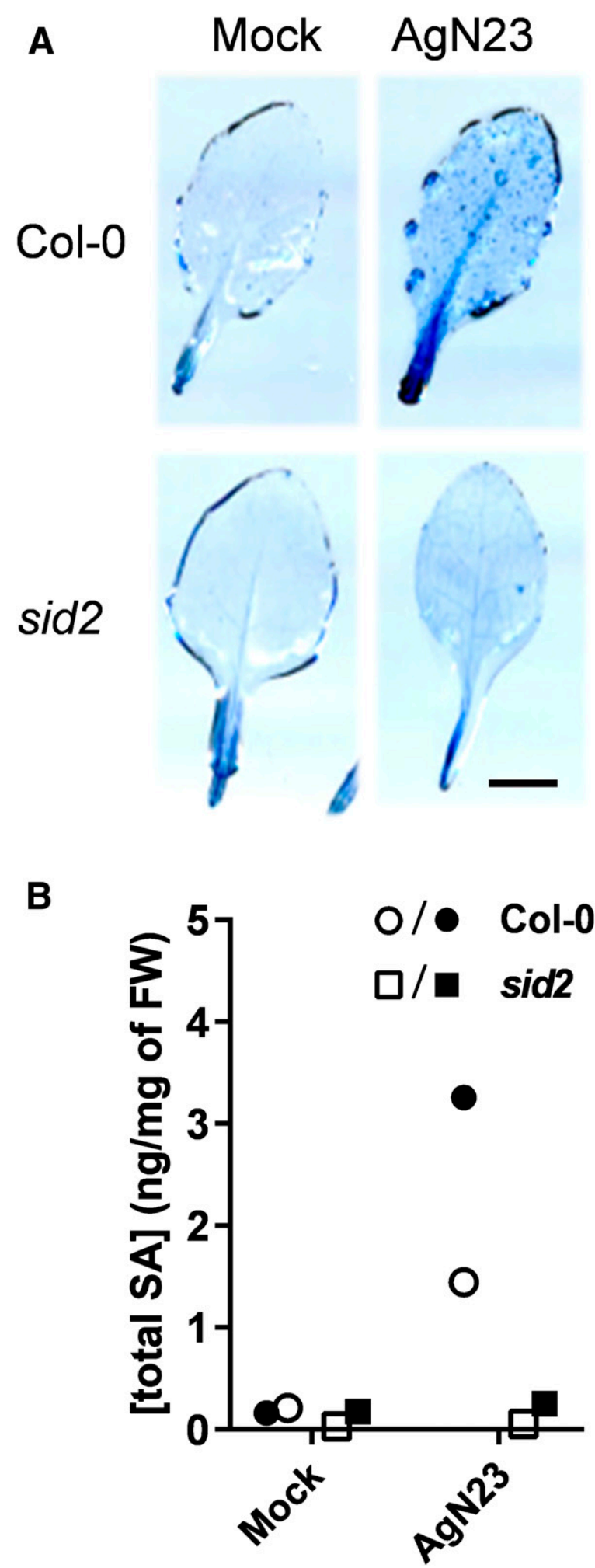

Fig. 5. AgN23 culture medium induces necrotic lesions triggered by the accumulation of salicylic acid (SA). A, Trypan Blue staining of leaves from wild-type Col-0 and the sid2-2 line; no lesions were observed on the sid2-2treated leaf (scale bar $=1 \mathrm{~cm}$ ). B, Quantification of total SA in Col-0 and sid2 at 1 day posttreatment (dpt) following treatment with Streptomyces sp. AgN23 cell suspension; $n=2$ independent biological replicates displayed separately by black and white dots. 
GUS buffer (100 mM phosphate buffer [pH 7], 0.1\% TritonX100 , and $10 \mathrm{mM} \beta$-mercaptoethanol). To quantify proteins, $200 \mu \mathrm{l}$ of Bradford reagent (Bio-Rad Laboratories, Marnes-laCoquette, France) was added to $10 \mu \mathrm{l}$ of samples. After incubation $\left(15 \mathrm{~min}\right.$ at $\left.25^{\circ} \mathrm{C}\right)$, absorbance was measured at $565 \mathrm{~nm}$. Standard curve was done with 1 to $20 \mu \mathrm{g}$ of bovine serum albumin (Sigma-Aldrich). Glucuronidase activity was determined with $25 \mu \mathrm{l}$ of protein extracts and $1 \mathrm{mM}$ 4-methylumbelliferyl glucuronide (MUG) (Sigma-Aldrich) in a total reaction volume of $200 \mu \mathrm{l}$. Fluorescence generated by MUG metabolization was measured every 5 min during $120 \mathrm{~min}$ on a TriStar LB 941 Multimode Microplate Reader (Berthold Technologies, Thoiry, France) at $37^{\circ} \mathrm{C}$ with excitation of $360 \mathrm{~nm}$ and emission of $460 \mathrm{~nm}$. Glucuronidase activity was calculated from the linear part of the reaction (between 20 and $100 \mathrm{~min}$ ) and normalized as nanokatals per milligram of total proteins.

\section{Genomic DNA extraction and PCR amplification for AgN23 16S ribosomal DNA sequencing.}

Genomic DNA was extracted from AgN23 mycelium after centrifugation of a 48-h liquid culture. Extraction was done using NucleoBond AXG columns and NucleoBond Buffer Set III (Macherey Nagel, Hoerdt, France). The 16S ribosomal DNA was amplified from gDNA by PCR using $5^{\prime}$-AGAGTTTG ATCCTGGCTCAG-3' and 5'-GGTTACCTTGTTACGACTT-3' primers. Sanger sequencing was performed at the GeT-PlaGe core facility, Toulouse, France.

\section{RNA isolation and analysis of gene expression by RT-qPCR.}

Total RNA was extracted using the SV Total RNA Isolation System kit (Promega, Charbonnières, France). For each sample, $1 \mu \mathrm{g}$ of total RNA was reverse-transcribed with the HighCapacity cDNA Reverse-Transcription Kit (Applied Biosystems, Courtaboeuf, France). High-throughput qPCR was performed using the BioMark HD System (Fluidigm, Issy les Moulineaux, France). Briefly, cDNAs were diluted to approximately $50 \mathrm{ng} / \mu \mathrm{l}$ prior to being submitted to specific target amplification by 14 cycles of PCR amplification $\left(95^{\circ} \mathrm{C}\right.$ for $15 \mathrm{~s}$ and $60^{\circ} \mathrm{C}$ for $4 \mathrm{~min}$ ) in a reaction mix containing the 96 primer pairs (50 nM) and the TaqMan PreAmp Master Mix (1:2) (Applied Biosystems). Primer sequences are available in supplementary materials from Vergnes et al. (2014). Preamplified cDNAs were diluted with Tris-EDTA buffer (1:5) and used for
qPCR array analysis in a reaction mix containing TaqMan Gene Expression Master Mix, DNA Binding Dye Sample Loading Reagent, and EvaGreen. Data were analyzed with the BioMark Real-Time PCR Analysis Software (version 2.0; Fluidigm, Les Ulis, France), The NormFinder software (Andersen et al. 2004) was used to determine the best housekeeping genes and the clathrin gene AT5G46630 was retained for normalization. Relative gene expression was calculated over three independent experiments and significant gene deregulations were determined by Student's $t$ test.

\section{RNAseq experiment and analysis.}

The same RNA samples prepared for RT-qPCR were used for RNAseq experiments. RNAseq libraries were prepared according to Illumina's protocols using the Illumina TruSeq Stranded mRNA Sample Prep Kit to analyze mRNA, at the GeT-PlaGe core facility, Toulouse, France (Gaulin et al. 2018). Briefly, mRNA was selected using poly-T beads, cDNA was generated using random hexamer priming, and adapters were then added. Ten cycles of PCR were applied to amplify the libraries. Library quality was assessed using an Agilent Bioanalyzer, and the libraries were quantified by qPCR using the Kapa Library Quantification Kit. RNAseq experiments were performed on an Illumina HiSeq2500 using a paired-end read length of $2 \times 100 \mathrm{pb}$ with the Illumina TruSeq SBS Sequencing Kits v3. The resulting FASTQ files contained 452,736,864 reads for $\mathrm{AgN} 23$ treatment and $415,999,444$ reads for the control. The quality control was performed on raw sequencing datasets using FastQC. The paired-end reads were mapped to the Arabidopsis TAIR10 genome reference using CLC Genomics Workbench version 8.5.1 with default parameters and expressed as reads per kilobase per million mapped reads (Supplementary Dataset S2). Gene regulation was determined using two-by-two comparisons between Actilandes-treated and AgN23-treated samples at each timepoint with the "Empirical Analysis of Differential Gene Expression" pipeline of the software (Supplementary Dataset S2). Briefly, the test is based on the assumption that the count data follows a negative binomial distribution. The "Exact Test" of Robinson and Smyth is similar to Fisher's exact test but also accounts for overdispersion caused by biological variability. Whereas Fisher's exact test compares the counts in one sample against those of another, the Exact Test compares the counts in one set of count samples against those in another set of count samples. The Exact Test in the EdgeR
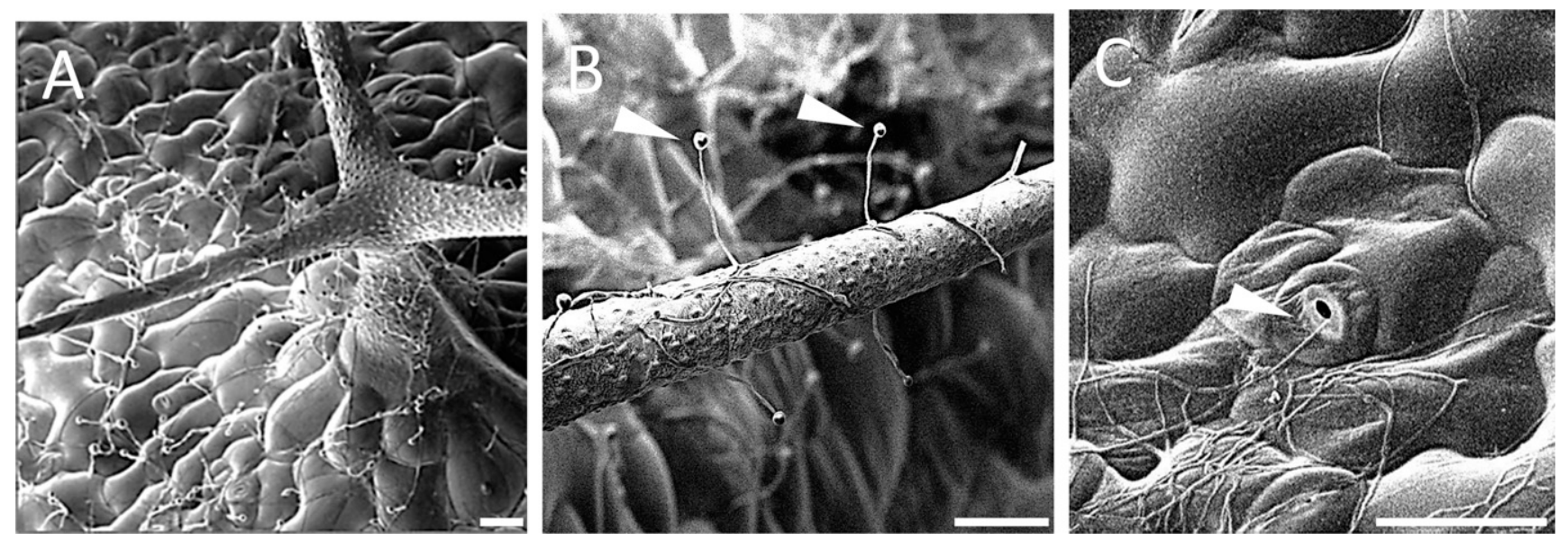

Fig. 6. Development of AgN23 on the surface of Arabidopsis leaves. A, Hyphal development at 7 days postinoculation with a 7-day-old liquid culture on the adaxial face of the leaf. B, Growth of the mycelium on a trichome branch; hyphae are terminated by sporangium-like structures (arrowheads). C, Cell death response of stomata observed upon colonization by AgN23 hyphae (arrowhead). Scale bars $=25 \mu \mathrm{m}$. 
Bioconductor package provides the user with the option to set a large number of parameters. The implementation of the "Empirical analysis of DGE" algorithm in the Genomics Workbench uses, for the most part, the default settings in the edgeR package, version 3.4.0.

In the end, we only considered genes with a twofold induction or repression between treated and untreated situations and a $P$ value $<0.001$ after correction with the FDR method developed by Benjamini and Hochberg (Supplementary Dataset
S2). Raw data can be found on the NCBI Gene Expression Omnibus (GSE119986).

\section{Microscopy.}

The observation of AgN23 development on Arabidopsis leaves was performed using scanning electronic microscopy on an FEG FEI Quanta 250. Leaf samples were placed on the micrometric platen of the scanning electron microscope before being frozen in liquid nitrogen and metallized with platinum.
Col-0

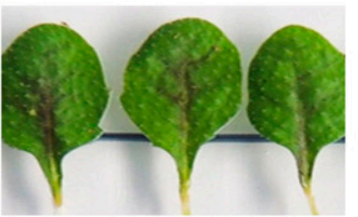

Mock

AgN23
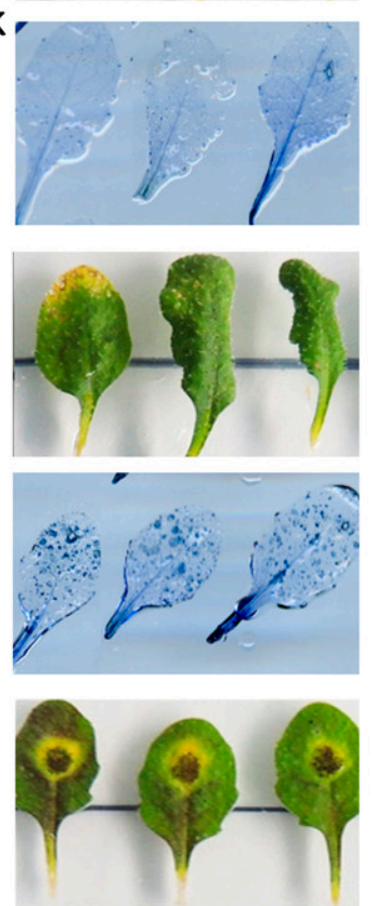

\section{A. brassicicola}
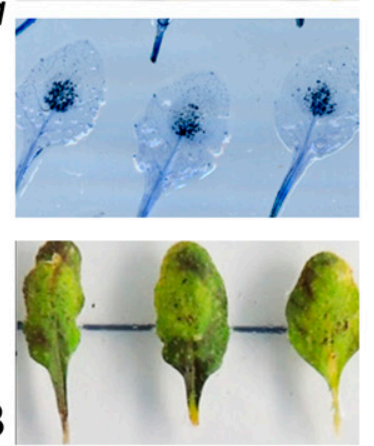

AgN23

\section{A. brassicicola}

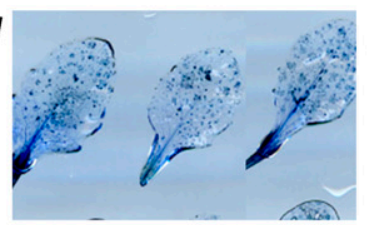

sid2
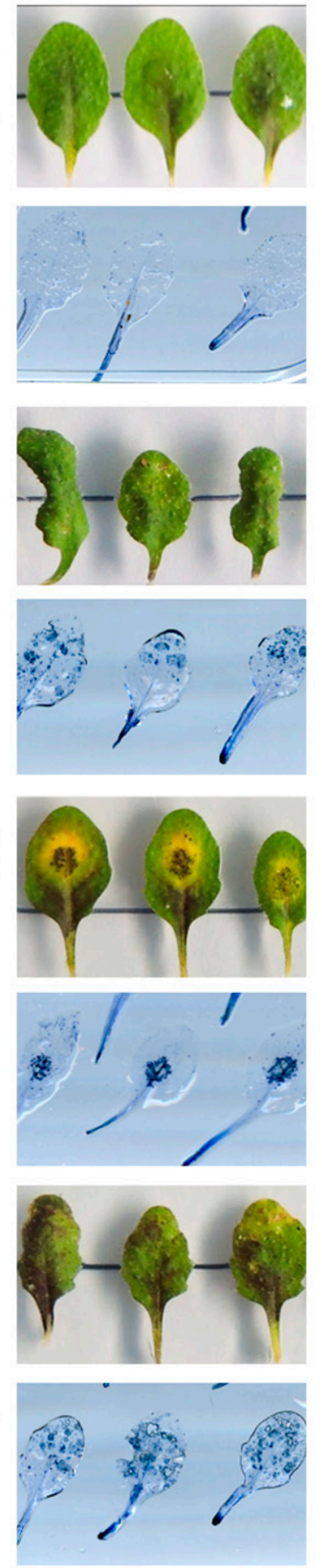

jar1
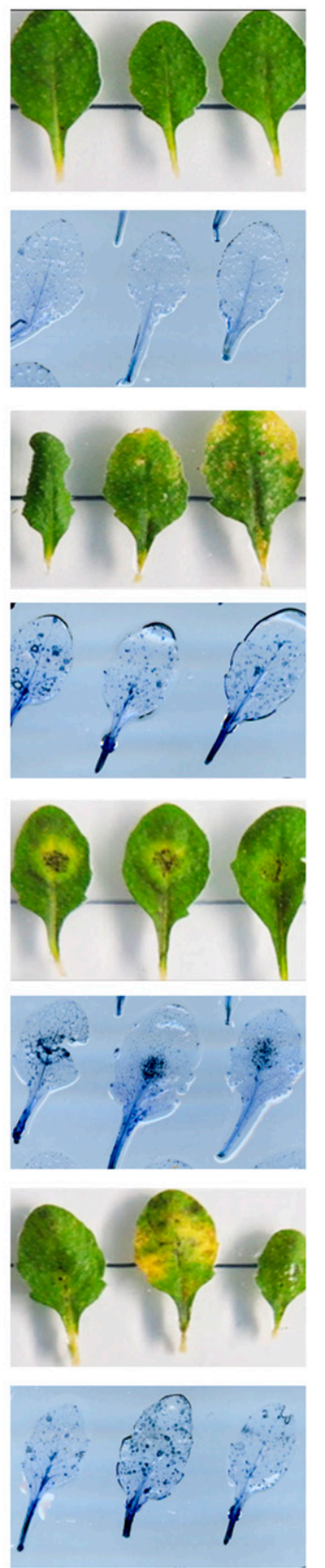

ein2
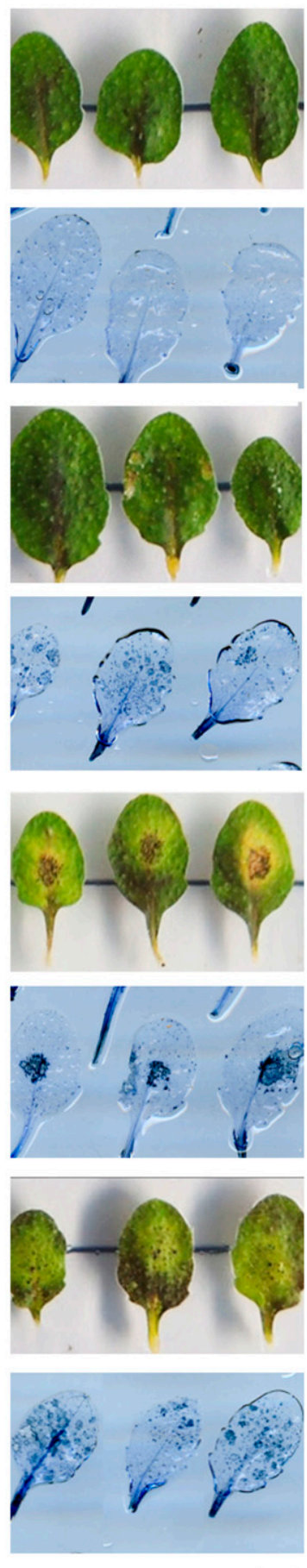

Fig. 7. AgN23-mediated protection of Arabidopsis leaves against Alternaria brassicicola. Symptoms were observed at 6 days postinoculation of Col-0, sid2, jarl, and ein 2 leaves inoculated with a suspension of A. brassicicola conidia deposited in the center of the leaves. Treatment with AgN23 was performed by spraying a bacterial suspension from a 7-day-old culture on the surface of the leaves. For each treatment, leaves were subjected to Trypan Blue staining to visualize necrotic lesions. Scale bar $=1 \mathrm{~cm}$. 
Materials were examined microscopically at an accelerating voltage of $5.00 \mathrm{kV}$.

To detect necrotic areas in Arabidopsis leaves, we used a Trypan staining solution containing $10 \mathrm{~g}$ of phenol, $10 \mathrm{ml}$ of glycerol, $10 \mathrm{ml}$ of lactic acid, $10 \mathrm{ml}$ of ultrahigh-quality water, and $0.02 \mathrm{~g}$ of Trypan Blue in $60 \mathrm{ml}$ of pure ethanol. Leaf material was placed in a 2-ml tube with Trypan Blue solution, boiled for $1 \mathrm{~min}$, and left overnight in the staining solution at $20^{\circ} \mathrm{C}$. The samples were washed two times in chloral hydrate destaining solution (1 kg of chloral hydrate in $400 \mathrm{ml}$ of water).

\section{SA quantification.}

Determination of SA content was performed according to Vergnes et al. (2014). Briefly, $100 \mathrm{mg}$ of leaf tissue was ground in liquid nitrogen, and $50 \mathrm{ng}$ of an internal standard (o-anisic acid [oANI]) was added before the extraction of total SA. Total SA (free SA and SA conjugates) was extracted by methanolic extraction followed by acid hydrolysis. The hydrolysate was then subjected to organic phase partitioning (ether). Organic phase was evaporated and the sample diluted with $100 \mu \mathrm{l}$ of acetonitrile-water-formic acid (50:50:0.1\% $[\mathrm{vol} / \mathrm{vol} / \mathrm{vol}])$. Analysis was performed with reverse-phase high-performance liquid chromatography (Ultimate 3000; Thermo Scientific) coupled with fluorescence detection (Jasco FP-920). SA and oANI were separated on an XBridge reverse-phase column ( $25 \mathrm{~cm}$ by $4.6 \mathrm{~mm}$ by $5 \mu \mathrm{m}$; Waters) and an XBridge guard column ( $2 \mathrm{~cm}$ by $4.6 \mathrm{~mm}$ by $5 \mu \mathrm{m}$; Waters) by gradient elution with a binary system of acetonitrile-waterformic acid. The mobile phase consisted of acetonitrileformic acid (100:0.1\% [vol/vol]) and water-formic acid (100: $0.1 \%$ [vol/vol]) at a flow rate of $0.8 \mathrm{ml} \mathrm{min}^{-1}$. Fluorescence detection set at excitation and emission wavelengths of 294 and $359 \mathrm{~nm}$, respectively, for oANI and 305 and $407 \mathrm{~nm}$ for SA. SA was quantified using Chromeleon 6.8 chromatography software (Thermo Scientific). Corrections for losses were made for each individual sample according to recoveries of the internal standard.

\section{Statistics.}

Depending on the number of variables, one-way or two-way analysis of variance followed by Tukey's or Dunnett's multiple comparisons tests were performed after checking the

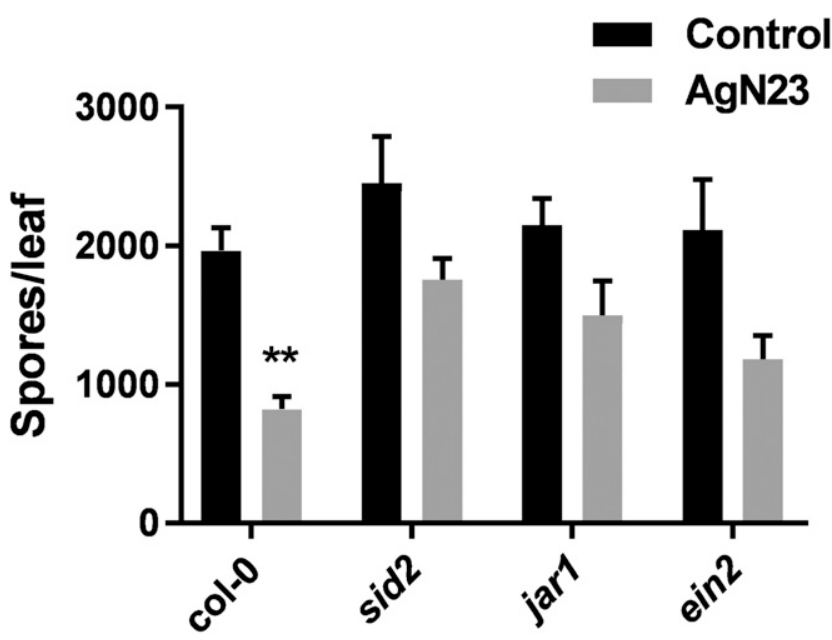

Fig. 8. Sporulation of Alternaria brassicicola on Arabidopsis leaves 6 days after inoculation. Leaves were treated with water or AgN23 48 h before inoculation. Error bars represent standard error of the mean of $n=3$ independent experiments; differences in spore counts were assessed using two-way analysis of variance followed by Dunnett's multiple comparison test (** indicates $P<0.01$ ). assumptions of normality by the Shapiro-Wilk test and equality of variance by the Brown-Forsythe test using GraphPad Prism version 7.05 for Windows. The test used for each dataset is stated in the figure legends.

\section{Accession numbers.}

Datasets generated or analyzed during this study are included in this published article (and its Supplementary Dataset files). Raw data regarding RNAseq analysis can be found on the NCBI Gene Expression Omnibus (GSE119986). The Streptomyces sp. AgN23 16S rRNA gene partial sequence was deposited on GenBank under the accession JN104730.1.

\section{ACKNOWLEDGMENTS}

We thank C. Campion and P. Simoneau (UMR 1345 IRHS, Angers) for kindly providing Alternaria brassiscicola strain Abra43, N. Ladouce (Laboratoire de Recherche en Sciences Végétales) for help with the BioMark Fluidigm analysis, S. Fournier for SA analysis, and V. Arnal (De Sangosse) for helpful comments on the manuscript.

\section{AUTHOR-RECOMMENDED INTERNET RESOURCES}

Empirical analysis of DGE: http://resources.qiagenbioinformatics. $\mathrm{com} / \mathrm{manuals} / \mathrm{clcgenomicsworkbench/750/index.php?manual=}$ Empirical_analysis_DGE.html

Corrected $P$ values: http://resources.qiagenbioinformatics. com/manuals/clcgenomicsworkbench/900/index.php?manual= Corrected_p_values.html

\section{LITERATURE CITED}

Alonso, J. M., Hirayama, T., Roman, G., Nourizadeh, S., and Ecker, J. R. 1999. EIN2, a bifunctional transducer of ethylene and stress responses in Arabidopsis. Science 284:2148-2152.

Andersen, C. L., Jensen, J. L., and Ørntoft, T. F. 2004. Normalization of real-time quantitative reverse transcription-PCR data: A model-based variance estimation approach to identify genes suited for normalization, applied to bladder and colon cancer data sets. Cancer Res. 64:5245-5250.

Armijos-Jaramillo, V., Santander-Gordón, D., Soria, R., Pazmiño-Betancourth, M., and Echeverría, M. C. 2017. A whole genome analysis reveals the presence of a plant PR1 sequence in the potato pathogen Streptomyces scabies and other Streptomyces species. Mol. Phylogenet. Evol. 114:346-352.

Bakker, M. G., Schlatter, D. C., Otto-Hanson, L., and Kinkel, L. L. 2014. Diffuse symbioses: Roles of plant-plant, plant-microbe and microbemicrobe interactions in structuring the soil microbiome. Mol. Ecol. 23: 1571-1583.

Barka, E. A., Vatsa, P., Sanchez, L., Gaveau-Vaillant, N., Jacquard, C., Meier-Kolthoff, J. P., Klenk, H. P., Clément, C., Ouhdouch, Y., and van Wezel, G. P. 2015. Taxonomy, physiology, and natural products of actinobacteria. Microbiol. Mol. Biol. Rev. 80:1-43.

Berendsen, R. L., Pieterse, C. M., and Bakker, P. A. 2012. The rhizosphere microbiome and plant health. Trends Plant Sci. 17:478-486.

Bergelson, J., Mittelstrass, J., and Horton, M. W. 2019. Characterizing both bacteria and fungi improves understanding of the Arabidopsis root microbiome. Sci. Rep. 9:24.

Betsuyaku, S., Katou, S., Takebayashi, Y., Sakakibara, H., Nomura, N., and Fukuda, H. 2018. Salicylic acid and jasmonic acid pathways are activated in spatially different domains around the infection site during effector-triggered immunity in Arabidopsis thaliana. Plant Cell Physiol. $59: 439$

Bhattacharyya, P. N., and Jha, D. K. 2012. Plant growth-promoting rhizobacteria (PGPR): Emergence in agriculture. World J. Microbiol. Biotechnol. 28:1327-1350.

Boller, T., and Felix, G. 2009. A renaissance of elicitors: Perception of microbe-associated molecular patterns and danger signals by patternrecognition receptors. Annu. Rev. Plant Biol. 60:379-406.

Bürger, M., and Chory, J. 2019. Stressed out about hormones: How plants orchestrate immunity. Cell Host Microbe 26:163-172.

Busby, P. E., Soman, C., Wagner, M. R., Friesen, M. L., Kremer, J., Bennett, A., Morsy, M., Eisen, J. A., Leach, J. E., and Dangl, J. L. 2017. Research priorities for harnessing plant microbiomes in sustainable agriculture. PLoS Biol. 15:e2001793. 
Cao, P., Liu, C., Sun, P., Fu, X., Wang, S., Wu, F., and Wang, X. 2016. An endophytic Streptomyces sp. strain DHV3-2 from diseased root as a potential biocontrol agent against Verticillium dahliae and growth elicitor in tomato (Solanum lycopersicum). Antonie Leeuwenhoek 109: 1573-1582.

Carvalhais, L. C., Dennis, P. G., Badri, D. V., Kidd, B. N., Vivanco, J. M., and Schenk, P. M. 2015. Linking jasmonic acid signaling, root exudates, and rhizosphere microbiomes. Mol. Plant-Microbe Interact. 28: 1049-1058.

Chandra, G., and Chater, K. F. 2014. Developmental biology of Streptomyces from the perspective of 100 actinobacterial genome sequences. FEMS Microbiol. Rev. 38:345-379.

Chaparro, J. M., Badri, D. V., Bakker, M. G., Sugiyama, A., Manter, D. K., and Vivanco, J. M. 2013. Root exudation of phytochemicals in Arabidopsis follows specific patterns that are developmentally programmed and correlate with soil microbial functions. PLoS One 8: e55731.

Chaparro, J. M., Badri, D. V., and Vivanco, J. M. 2014. Rhizosphere microbiome assemblage is affected by plant development. ISME J. 8: 790-803.

Chater, K. F., Biró, S., Lee, K. J., Palmer, T., and Schrempf, H. 2010. The complex extracellular biology of Streptomyces. FEMS Microbiol. Rev. 34:171-198

Conn, V. M., Walker, A. R., and Franco, C. M. 2008. Endophytic actinobacteria induce defense pathways in Arabidopsis thaliana. Mol. Plant-Microbe Interact. 21:208-218.

Cordovez, V., Carrion, V. J., Etalo, D. W., Mumm, R., Zhu, H., van Wezel, G. P., and Raaijmakers, J. M. 2015. Diversity and functions of volatile organic compounds produced by Streptomyces from a diseasesuppressive soil. Front. Microbiol. 6:1081.

Duval, I., and Beaudoin, N. 2009. Transcriptional profiling in response to inhibition of cellulose synthesis by thaxtomin A and isoxaben in Arabidopsis thaliana suspension cells. Plant Cell Rep. 28:811-830.

Errakhi, R., Bouteau, F., Lebrihi, A., and Barakate, M. 2007. Evidences of biological control capacities of Streptomyces spp. against Sclerotium rolfsii responsible for damping-off disease in sugar beet (Beta vulgaris L.). World J. Microbiol. Biotechnol. 23:1503-1509.

Ferrari, S., Plotnikova, J. M., De Lorenzo, G., and Ausubel, F. M. 2003 Arabidopsis local resistance to Botrytis cinerea involves salicylic acid and camalexin and requires EDS4 and PAD2, but not SID2, EDS5 or PAD4. Plant J. 35:193-205.

Frerigmann, H., Glawischnig, E., and Gigolashvili, T. 2015. The role of MYB34, MYB51 and MYB122 in the regulation of camalexin biosynthesis in Arabidopsis thaliana. Front. Plant Sci. 6:654.

Gaulin, E., Pel, M. J. C., Camborde, L., San-Clemente, H., Courbier, S., Dupouy, M. A., Lengellé, J., Veyssiere, M., Le Ru, A., Grandjean, F., Cordaux, R., Moumen, B., Gilbert, C., Cano, L. M., Aury, J. M., Guy, J., Wincker, P., Bouchez, O., Klopp, C., and Dumas, B. 2018. Genomics analysis of Aphanomyces spp. identifies a new class of oomycete effector associated with host adaptation. BMC Biol. 16:43.

Goodfellow, M., Kumar, Y., Labeda, D. P., and Sembiring, L. 2007. The Streptomyces violaceusniger clade: A home for Streptomycetes with rugose ornamented spores. Antonie Leeuwenhoek 92:173-199.

Hamedi, J., and Mohammadipanah, F. 2015. Biotechnological application and taxonomical distribution of plant growth promoting actinobacteria. J. Ind. Microbiol. Biotechnol. 42:157-171.

Hassan, N., Nakasuji, S., Elsharkawy, M. M., Naznin, H. A., Kubota, M., Ketta, H., and Shimizu, M. 2017. Biocontrol potential of an endophytic Streptomyces sp. strain MBCN152-1 against Alternaria brassicicola on cabbage plug seedlings. Microbes Environ. 32:133-141.

Hoefler, B. C., Stubbendieck, R. M., Josyula, N. K., Moisan, S. M., Schulze, E. M., and Straight, P. D. 2017. A link between linearmycin biosynthesis and extracellular vesicle genesis connects specialized metabolism and bacterial membrane physiology. Cell Chem. Biol. 24:1238-1249.e7.

Joglekar, S., Suliman, M., Bartsch, M., Halder, V., Maintz, J., Bautor, J., Zeier, J., Parker, J. E., and Kombrink, E. 2018. Chemical activation of EDS1/PAD4 signaling leading to pathogen resistance in Arabidopsis. Plant Cell Physiol. 59:1592-1607.

Jones, S. E., Ho, L., Rees, C. A., Hill, J. E., Nodwell, J. R., and Elliot, M. A. 2017. Streptomyces exploration is triggered by fungal interactions and volatile signals. Elife 6:e21738.

Joshi, M. V., Bignell, D. R., Johnson, E. G., Sparks, J. P., Gibson, D. M., and Loria, R. 2007. The AraC/XylS regulator TxtR modulates thaxtomin biosynthesis and virulence in Streptomyces scabies. Mol. Microbiol. 66: 633-642.

Kawamura, Y., Takenaka, S., Hase, S., Kubota, M., Ichinose, Y., Kanayama, Y., Nakaho, K., Klessig, D. F., and Takahashi, H. 2009. Enhanced defense responses in Arabidopsis induced by the cell wall protein fractions from Pythium oligandrum require SGT1, RAR1, NPR1 and JAR1. Plant Cell Physiol. 50:924-934.

Kinkel, L. L., Schlatter, D. C., Bakker, M. G., and Arenz, B. E. 2012. Streptomyces competition and co-evolution in relation to plant disease suppression. Res. Microbiol. 163:490-499.

Kumar, Y., Aiemsum-Ang, P., Ward, A. C., and Goodfellow, M. 2007. Diversity and geographical distribution of members of the Streptomyces violaceusniger $16 \mathrm{~S}$ rRNA gene clade detected by clade-specific PCR primers. FEMS Microbiol. Ecol. 62:54-63.

Kumar, Y., and Goodfellow, M. 2008. Five new members of the Streptomyces violaceusniger $16 \mathrm{~S}$ rRNA gene clade: Streptomyces castelarensis sp. nov., comb. nov., Streptomyces himastatinicus sp. nov., Streptomyces mordarskii sp. nov., Streptomyces rapamycinicus sp. nov. and Streptomyces ruanii sp. nov. Int. J. Syst. Evol. Microbiol. 58: 1369-1378.

Kurth, F., Mailänder, S., Bönn, M., Feldhahn, L., Herrmann, S., Große, I., Buscot, F., Schrey, S. D., and Tarkka, M. T. 2014. Streptomyces-induced resistance against oak powdery mildew involves host plant responses in defense, photosynthesis, and secondary metabolism pathways. Mol. Plant-Microbe Interact. 27:891-900.

Lee, H. A., Lee, H. Y., Seo, E., Lee, J., Kim, S. B., Oh, S., Choi, E., Choi, E., Lee, S. E., and Choi, D. 2017. Current understandings of plant nonhost resistance. Mol. Plant-Microbe Interact. 30:5-15.

Lehr, N. A., Schrey, S. D., Hampp, R., and Tarkka, M. T. 2008. Root inoculation with a forest soil streptomycete leads to locally and systemically increased resistance against phytopathogens in Norway spruce. New Phytol. 177:965-976.

Lerat, S., Babana, A. H., El Oirdi, M., El Hadrami, A., Daayf, F., Beaudoin, N., Bouarab, K., and Beaulieu, C. 2009. Streptomyces scabiei and its toxin thaxtomin A induce scopoletin biosynthesis in tobacco and Arabidopsis thaliana. Plant Cell Rep. 28:1895-1903.

Li, W., Ma, M., Feng, Y., Li, H., Wang, Y., Ma, Y., Li, M., An, F., and Guo, H. 2015. EIN2-directed translational regulation of ethylene signaling in Arabidopsis. Cell 163:670-683.

Li, X., Lai, X., Gan, L., Long, X., Hou, Y., Zhang, Y., and Tian, Y. 2018. Streptomyces geranii sp. nov., a novel endophytic actinobacterium isolated from root of Geranium carolinianum L. Int. J. Syst. Evol. Microbiol. 68:2562-2567.

Liu, G., Chater, K. F., Chandra, G., Niu, G., and Tan, H. 2013. Molecular regulation of antibiotic biosynthesis in Streptomyces. Microbiol. Mol. Biol. Rev. 77:112-143.

Lundberg, D. S., Lebeis, S. L., Paredes, S. H., Yourstone, S., Gehring, J., Malfatti, S., Tremblay, J., Engelbrektson, A., Kunin, V., Del Rio, T. G., Edgar, R. C., Eickhorst, T., Ley, R. E., Hugenholtz, P., Tringe, S. G., and Dangl, J. L. 2012. Defining the core Arabidopsis thaliana root microbiome. Nature 488:86-90.

Minamiyama, H., Shimizu, M., Kunoh, H., Furumai, T., Igarashi, Y., Onaka, H., and Yoshida, R. 2003. Multiplication of isolate R-5 of Streptomyces galbus on rhododendron leaves and its production of cell wall-degrading enzymes. J. Gen. Plant Pathol. 69:65-70.

Mingma, R., Duangmal, K., Thamchaipenet, A., Trakulnaleamsai, S., Matsumoto, A., and Takahashi, Y. 2015. Streptomyces oryzae sp. nov., an endophytic actinomycete isolated from stems of rice plant. J. Antibiot. (Tokyo) 68:368-372.

Niu, G., Chater, K. F., Tian, Y., Zhang, J., and Tan, H. 2016. Specialised metabolites regulating antibiotic biosynthesis in Streptomyces spp. FEMS Microbiol. Rev. 40:554-573.

Olanrewaju, O. S., and Babalola, O. O. 2019. Streptomyces: Implications and interactions in plant growth promotion. Appl. Microbiol. Biotechnol. 103:1179-1188.

Ondrejíčková, P., Šturdíková, M., Hushegyi, A., Švajdlenka, E., Markošová, K., and Čertík, M. 2016. Endophytic Streptomyces sp. AC35, a producer of bioactive isoflavone aglycones and antimycins. J. Ind. Microbiol. Biotechnol. 43:1333-1344.

Palaniyandi, S. A., Yang, S. H., Zhang, L., and Suh, J. W. 2013. Effects of actinobacteria on plant disease suppression and growth promotion. Appl. Microbiol. Biotechnol. 97:9621-9636.

Pieterse, C. M. J., Van der Does, D., Zamioudis, C., Leon-Reyes, A., and Van Wees, S. C. M. 2012. Hormonal modulation of plant immunity. Annu. Rev. Cell Dev. Biol. 28:489-521.

Pieterse, C. M. J., Zamioudis, C., Berendsen, R. L., Weller, D. M., Van Wees, S. C. M., and Bakker, P. A. H. M. 2014. Induced systemic resistance by beneficial microbes. Annu. Rev. Phytopathol. 52:347-375.

Pochon, S., Terrasson, E., Guillemette, T., Iacomi-Vasilescu, B., Georgeault, S., Juchaux, M., Berruyer, R., Debeaujon, I., Simoneau, P., and Campion, C. 2012. The Arabidopsis thaliana-Alternaria brassicicola pathosystem: A model interaction for investigating seed transmission of necrotrophic fungi. Plant Methods 8:16. 
Rajniak, J., Barco, B., Clay, N. K., and Sattely, E. S. 2015. A new cyanogenic metabolite in Arabidopsis required for inducible pathogen defence. Nature 525:376-379.

Rashad, F. M., Fathy, H. M., El-Zayat, A. S., and Elghonaimy, A. M. 2015. Isolation and characterization of multifunctional Streptomyces species with antimicrobial, nematicidal and phytohormone activities from marine environments in Egypt. Microbiol. Res. 175:34-47.

Rey, T., and Dumas, B. 2017. Plenty is no plague: Streptomyces symbiosis with crops. Trends Plant Sci. 22:30-37.

Riedlinger, J., Schrey, S. D., Tarkka, M. T., Hampp, R., Kapur, M., and Fiedler, H. P. 2006. Auxofuran, a novel metabolite that stimulates the growth of fly agaric, is produced by the mycorrhiza helper bacterium Streptomyces strain AcH 505. Appl. Environ. Microbiol. 72:3550-3557.

Sarmiento-Vizcaíno, A., Braña, A. F., González, V., Nava, H., Molina, A., Llera, E., Fiedler, H. P., Rico, J. M., García-Flórez, L., Acuña, J. L., García, L. A., and Blanco, G. 2016. Atmospheric dispersal of bioactive Streptomyces albidoflavus strains among terrestrial and marine environments. Microb. Ecol. 71:375-386.

Schrempf, H., Koebsch, I., Walter, S., Engelhardt, H., and Meschke, H. 2011. Extracellular Streptomyces vesicles: Amphorae for survival and defence. Microb. Biotechnol. 4:286-299.

Schrempf, H., and Merling, P. 2015. Extracellular Streptomyces lividans vesicles: Composition, biogenesis and antimicrobial activity. Microb. Biotechnol. 8:644-658.

Schrey, S. D., Salo, V., Raudaskoski, M., Hampp, R., Nehls, U., and Tarkka, M. T. 2007. Interaction with mycorrhiza helper bacterium Streptomyces sp. $\mathrm{AcH} 505$ modifies organisation of actin cytoskeleton in the ectomycorrhizal fungus Amanita muscaria (fly agaric). Curr. Genet. 52:77-85.

Schrey, S. D., Schellhammer, M., Ecke, M., Hampp, R., and Tarkka, M. T. 2005. Mycorrhiza helper bacterium Streptomyces AcH 505 induces differential gene expression in the ectomycorrhizal fungus Amanita muscaria. New Phytol. 168:205-216.

Schrey, S. D., and Tarkka, M. T. 2008. Friends and foes: Streptomycetes as modulators of plant disease and symbiosis. Antonie Leeuwenhoek 94: 11-19.

Seipke, R. F., Kaltenpoth, M., and Hutchings, M. I. 2012. Streptomyces as symbionts: An emerging and widespread theme? FEMS Microbiol. Rev. 36:862-876.

Sellam, A., Dongo, A., Guillemette, T., Hudhomme, P., and Simoneau, P. 2007. Transcriptional responses to exposure to the brassicaceous defence metabolites camalexin and allyl-isothiocyanate in the necrotrophic fungus Alternaria brassicicola. Mol. Plant Pathol. 8:195-208.

Shao, Z., Li, Z., Fu, Y., Wen, Y., and Wei, S. 2018. Induction of defense responses against Magnaporthe oryzae in rice seedling by a new potential biocontrol agent Streptomyces JD211. J. Basic Microbiol. 58: 686-697.

Shapiro, A. D., and Zhang, C. 2001. The role of NDR1 in avirulence genedirected signaling and control of programmed cell death in Arabidopsis. Plant Physiol. 127:1089-1101.

Shimizu, M., Nakagawa, Y., Sato, Y., Furumai, T., Igarashi, Y., Onaka, H., Yoshida, R., and Kunoh, H. 2000. Studies on endophytic actinomycetes (I) Streptomyces sp. isolated from rhododendron and its antifungal activity. J. Gen. Plant Pathol. 66:360-366.

Staswick, P. E., Yuen, G. Y., and Lehman, C. C. 1998. Jasmonate signaling mutants of Arabidopsis are susceptible to the soil fungus Pythium irregulare. Plant J. 15:747-754.

Stringlis, I. A., Proietti, S., Hickman, R., Van Verk, M. C., Zamioudis, C., and Pieterse, C. M. J. 2018a. Root transcriptional dynamics induced by beneficial rhizobacteria and microbial immune elicitors reveal signatures of adaptation to mutualists. Plant J. 93:166-180.

Stringlis, I. A., Yu, K., Feussner, K., de Jonge, R., Van Bentum, S., Van Verk, M. C., Berendsen, R. L., Bakker, P. A. H. M., Feussner, I., and Pieterse, C. M. J. 2018b. MYB72-dependent coumarin exudation shapes root microbiome assembly to promote plant health. Proc. Natl. Acad. Sci. U.S.A. 115:E5213-E5222.

Supek, F., Bošnjak, M., Škunca, N., and Šmuc, T. 2011. REVIGO summarizes and visualizes long lists of gene ontology terms. PLoS One 6:e21800.

Syed Ab Rahman, S. F., Singh, E., Pieterse, C. M. J., and Schenk, P. M. 2018. Emerging microbial biocontrol strategies for plant pathogens. Plant Sci. 267:102-111.

Tarkka, M. T., Feldhahn, L., Buscot, F., and Wubet, T. 2015. Genome sequence of the mycorrhiza helper bacterium Streptomyces sp. strain AcH 505. Genome Announce. 3:e01386-14.

van der Meij, A., Willemse, J., Schneijderberg, M. A., Geurts, R., Raaijmakers, J. M., and van Wezel, G. P. 2018. Inter- and intracellular colonization of Arabidopsis roots by endophytic actinobacteria and the impact of plant hormones on their antimicrobial activity. Antonie Leeuwenhoek 111:679-690.

van Loon, L. C., Bakker, P. A., and Pieterse, C. M. 1998. Systemic resistance induced by rhizosphere bacteria. Annu. Rev. Phytopathol. 36: 453-483.

Varma Penmetsa, R., Uribe, P., Anderson, J., Lichtenzveig, J., Gish, J.-C., Nam, Y. W., Engstrom, E., Xu, K., Sckisel, G., Pereira, M., Baek, J. M., Lopez-Meyer, M., Long, S. R., Harrison, M. J., Singh, K. B., Kiss, G. B., and Cook, D. R. 2008. The Medicago truncatula ortholog of Arabidopsis EIN2, sickle, is a negative regulator of symbiotic and pathogenic microbial associations. Plant J. 55:580-595.

Vergnes, S., Ladouce, N., Fournier, S., Ferhout, H., Attia, F., and Dumas, B. 2014. Foliar treatments with Gaultheria procumbens essential oil induce defense responses and resistance against a fungal pathogen in Arabidopsis. Front. Plant Sci. 5:477.

Viaene, T., Langendries, S., Beirinckx, S., Maes, M., and Goormachtig, S. 2016. Streptomyces as a plant's best friend? FEMS Microbiol. Ecol. 92: fiw119.

Vorholt, J. A. 2012. Microbial life in the phyllosphere. Nat. Rev. Microbiol. 10:828-840.

Vurukonda, S. S. K. P., Giovanardi, D., and Stefani, E. 2018. Plant growth promoting and biocontrol activity of Streptomyces spp. as endophytes. Int. J. Mol. Sci. 19:952-978.

Wang, C., Liu, R., Lim, G.H., de Lorenzo, L., Yu, K., Zhang, K., Hunt, A.G., Kachroo, A., and Kachroo, P. 2018. Pipecolic acid confers systemic immunity by regulating free radicals. Sci. Adv. 4:eaar4509.

Wang, Y., Liu, C., Li, K., Sun, F., Hu, H., Li, X., Zhao, Y., Han, C., Zhang, W., Duan, Y., Liu, M., and Li, X. 2007. Arabidopsis EIN2 modulates stress response through abscisic acid response pathway. Plant Mol. Biol. 64:633-644.

Wildermuth, M. C., Dewdney, J., Wu, G., and Ausubel, F. M. 2001. Isochorismate synthase is required to synthesize salicylic acid for plant defence. Nature 414:562-565.

Zhao, S., Du, C. M., and Tian, C. Y. 2012. Suppression of Fusarium oxysporum and induced resistance of plants involved in the biocontrol of cucumber Fusarium wilt by Streptomyces bikiniensis HD-087. World J. Microbiol. Biotechnol. 28:2919-2927.

Zipfel, C. 2008. Pattern-recognition receptors in plant innate immunity. Curr. Opin. Immunol. 20:10-16. 